\title{
Research on Sports Sponsorship Effectiveness
}

\author{
Hailang Yu \\ Business school \\ Sichuan University \\ Chengdu, P.R.China
}

\author{
Qinyu Tan \\ Business school \\ Sichuan University \\ Chengdu, P.R.China
}

\begin{abstract}
With the vigorous development of sports sponsorship market, sports sponsorship has increasingly become an important means of communication to enhance the image of enterprises and highly achieve the enterprise goals. Based on the analysis of the sports sponsorship effectiveness and the impact factors of sports sponsorship effectiveness, this paper establishes the sports sponsorship effectiveness evaluation mode from three perspectives, that is, from customers' perspective, from cooperative perspective, from social benefits perspective.
\end{abstract}

Keywords-sports sponsorship effectiveness; effect factors; effectiveness evaluation

\section{INTRODUCTION}

According to Statista 2016 annual report, the global sports sponsorship investment reached $\$ 60.2$ billion in 2016 , increased by $4.7 \%$ compared with the last year. Thus, the sports sponsorship market has been developing rapidly. Sports event sponsorship is one of the effective ways for modern enterprise marketing. For sponsoring enterprises, it can enhance the visibility of enterprises, increase product sales, improve market competitiveness, and create favorable survival and development environment for enterprises. But for the recipients, it can benefit from the human resources, materials and financial resources of the enterprise through exchanging the rights to exchange resources and interests. It is admitted that in today's integration of sports and business, sponsoring sports events is not only the tangible resources for the two parties. If the sponsor enterprise is a strong brand, the brand effect will be spread to the field of sports sponsorship, so as to enhance the brand image, improve commercial value of the sports events and also achieve sports marketing purposes. Therefore, it is particularly important to study the sports sponsorship effectiveness, its effect factors and how to construct the evaluation model of sports sponsorship effectiveness.

\section{DEFINITION OF SPORTS SPONSORSHIP}

The scholars have different titles for sports sponsorship, which is translated into sports sponsorship marketing. And Taiwan scholars call it sports sponsorship. In this study, sports sponsorship marketing or sports sponsorship are unified as sports sponsorship.

Sleight (1989) pointed out that sports sponsorship is a business relationship, which exists between resource providers and sports activities or sports organizations. The former affords some funds, resources or services, and then the later will grant some rights to the enterprise as a commercial benefit feedback [1]. Brooks (1990) thought that sports sponsorship is the enterprise that purchase rights from sports (including cash, product or service), then connected the symbol of sports activities and corporate image in order to pursue corporate propaganda and target market, and finally convert it to the benefit of the enterprise [2]. McCarville and Copeland (1994) believed that sports sponsorship is a process of exchange between enterprises and sports organizations. It is the enterprise which provide paid resources (money, equipment, facility and other items) and free resources (staff, technology, service, ideas and so on) in exchange for opportunities interconnected with sports events and sports activities. Finally it will find its ways to improve the image and reputation of enterprise and product and also gain greater marketing chances [3]. Bao Mingxiao (2000) believed that sports sponsorship refers to a special business act with sports as the theme, support and return as the content, the exchange of interests as the form, and achieving their own organizational goals as the purpose [4]. Huang Ke (2001) thought that sports sponsorship is pointing to a certain amount of cash or in kind paid to a physical asset (sports events, sports stadiums, public sports activities and etc.) as a special commercial behavior with the physical asset involved in the development project to achieve their own organizational goals for the final purpose[5]. Yu Chengshi (2007) considered that sports sponsorship is a modern market trading method that one party provides material support to the other party to achieve its intended business or social goals and expects to receive returns [6]. Huang Shuru (1999) deemed that sports sponsorship is carried out through the exchange of interests. Sponsoring enterprises provide funds and products, and take sports sponsorship as a tool to communicate with customers. Enterprises provide sports sponsorship, which can improve the visibility, corporate image and sales performance and other benefits [7].

According to the domestic and foreign scholars on sports sponsorship, we can see that sports sponsorship is the product of a certain stage of development of sports and commercial activities, although the definition of scholars are not unified, but in essence it is basically a kind of commercialism with commercial agreements between the enterprise and sports organizations. 


\section{SPORTS SPONSORSHIP EFFECTIVENESS}

The sports sponsorship effectiveness mainly displays in the following five aspects: custromer-based brand equity, brand integration, brand loyalty, sponsor image, Stakeholders.

\section{A. Brand Equity}

It is necessary to mention that one important objective of sports sponsorship is to increase brand equity which refers to a value premium that a company generates from a product or a service with a recognizable name. Brand equity has five basic components: cognitive effects, negative or positive effects, behavioral responses, purchase commitment and purchasing behavior. First and foremost, brand equity is built by consumer cognitive process, which includes both awareness and image with a brand and its products. Then consumers hold about a brand directly results in either positive or negative effects. Finally, these effects can turn into consumers purchasing behaviors.

\section{B. Brand Integration}

Brand integration is the inclusion of branded products or identifiers through audio or visual means within mass media programming (Balasubramanian, 1994) [8].Brand integration is frequently a central component of a sponsorship-linked marketing effort, which is defined as "marketing activities for the purpose of building and communicating an association to a sponsorship" (Cornwell, 1995)[9].

\section{Brand Loyalty}

When consumers become committed to brands and make repeat purchases from the same brands over time after sports sponsorship, sponsors could agree that they cultivate consumers brand loyalty successfully. In a competitive marketplace, brands need to maintain continuous meaningful engagement in order to keep the fresh and deep impression on customers. Brands are most successful when they address sports sponsorship that is important to their target customers, especially some crazy fans. This is celebrity effect for the company and is often an effective way of building brand loyalty.

\section{Sponsor Image}

Consequently, managers rank the promotion of corporate and brand image as their most important sponsorship goals. Sponsorships capture a significant proportion of marketing budgets. Infirm evaluations of the effectiveness of sponsorship engagements, image improvements represent the most important company objective. This study develops and tests a framework for explaining how exposure and activity involvement moderate the effects of event image, eventsponsor fit, and event commercialization on sponsor image. Using empirical data collected at a large sporting event with multiple sponsors, the authors show that increased sponsorship exposure reduces sponsor image if respondents perceive a low fit between the event and sponsor or high levels of event commercialization. Involvement in the sponsored activity improves the sponsor's image, in that the effect of event commercialization is positive for highly involved persons. This paper concludes with some reasons for the findings, implications for the choice and design of sponsorships, and further areas for research (Grohs and Reisinger 2014) [10].

\section{E. Stakeholders}

Various stakeholders may be affected whether the sponsorship is effective or not. Some are internal parties and under the control of the company. Some are external parties and beyond the control of the company. More specifically, these stakeholders include employees, stockholders, customers and others.

In internal parties, its marketing and internal branding play an important role for the success of the organization by sports sponsorship. The purpose of internal marketing is to transfer brand commitment into employees' commitment to enterprise, meanwhile, cultivating more loyal, creative, and energetic staff. On the other hand, sports sponsorship can attract ideal employee by promoting corporate awareness and positive vision. It is obvious that sponsorship is closely related to employee morale, employee commitment, and employee service intention. For stockholders party, the attitudes of stockholders towards sponsorship can greatly affect the share price and even cooperate earnings. If the investors believe that sponsorship is an valuable investment, then the share price will rise accordingly. There is a strong link between team performance and sponsors' realized brand exposure and price paid. Price also was influenced by sponsorship level, functional congruence and, at the lowest level of sponsorship, shared nationality. For example, using NFL data researches find that stocks returning to the sponsoring firms are affected by the outcomes of games played in their stadiums. The mean difference between nextday abnormal returns after a win and after a loss of the home team is 56 basis points for Monday night games and 92 basis points for post-season elimination games. Evidence suggests that this effect is partially driven by investor sentiment.

In external parties, establishing and maintaining relationship with consumers is more valuable than winning short-term customers. In order to solve this situation, brands must address emotional values that are important to their target customers. It is obvious that sports sponsorship is a combination of sports spirits, corporate purpose, enterprise spirit, and other correlation between sponsoring companies and sponsored sports. Sports sponsorship plays a role in promoting customer trust and customer commitment, and then stimulating purchase intention in "Fig. 1". 


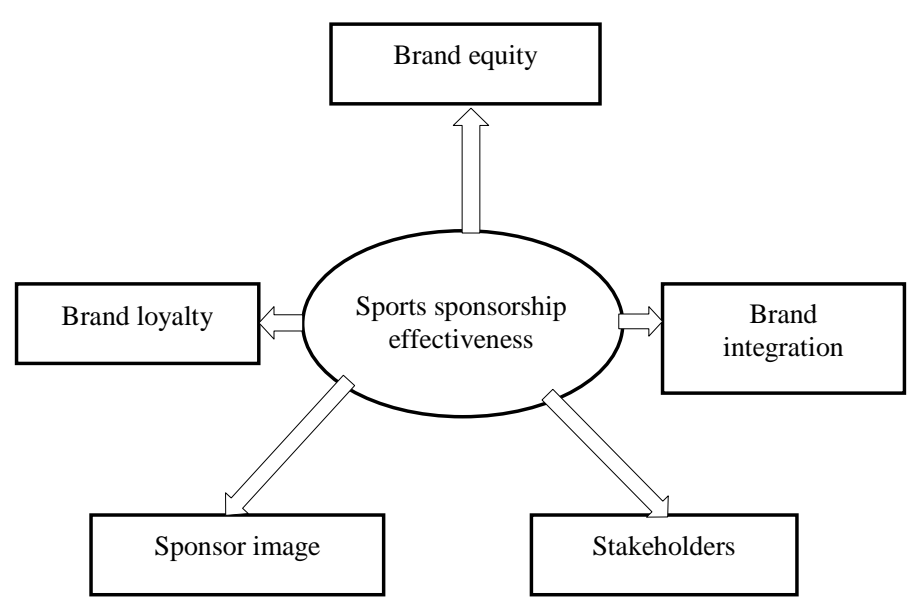

Fig. 1. Sports sponsorship effectiveness mode.

\section{THE INFLUENCING FACTORS OF SPORTS SPONSORSHIP EFFECTIVENESS}

Existing research has pointed out that three factors will significantly affect the Sports Sponsorship effectiveness: consumer characteristics factors, cognitive processing factors, and environmental factors.

\section{A. Consumer Characteristic Factors}

The individual characteristics of the target group determine the level of their response to sponsorship. The consumer's personal factors, including individual involvement, attitude towards sponsorship, perceived authenticity of the sponsors, familiarity with the sponsorship of the brand, perceived fit and demographic characteristics.

- Individual involvement. The sponsors and sports involvement will influence the sports sponsorship effects. This is because, from the exposure theory and consumer category knowledge, consumer involvement can increase the exposure, and makes consumers deal with sponsorship information more effectively and accurately (Madrigal, 2000) [11].

- Attitude towards sponsorship. It includes consumers' initial attitudes towards sponsors and sports events, attitudes of consumers toward sports sponsorship, attitudes of consumers to sponsorship events, and attitudes of consumers to sponsoring Enterprises

- Perceived sincerity of the sponsor. The consumer perception of sponsor motivation significantly affects their sponsorship attitude, emotional reaction and cross reaction. Consumers can trigger a better response if they think sponsors are genuinely committed to sponsoring activities and serving sponsors (Olson, 2010) [12].

- Familiarity with sponsors. Consumers' familiarity with sponsorship brands is the key factor affecting consumer sponsorship cognitive processing (Walraven and Koning, 2012) [13]. When consumers are familiar with the brand sponsorship, they are more likely to identify sponsor brand (Pestana Barros and
Silvestre, 2006) [14], and prominent brands are more likely to be recalled than the well-known brands. (Pham and Johar, 2001)[15].

- Population characteristics. Gender and education level are important demographic variables in marketing sponsorship awareness. Men are more likely to recall their sponsors than women. Consumers with higher educational background are more likely to identify sponsors than consumers with low educational background. While younger age negatively influences sponsorship awareness, young consumers have a higher awareness of sponsorship than older consumers (Kinney and McDaniel, 2008) [16].

\section{B. Cognitive Processing Factors}

Increased Cognitive processing factors include mere exposure low-level cognitive processing, stimulus reactivation, matching, and sponsorship relationship interpretation and so on.

- From the point view of pure exposure. Simply repeated exposure to certain stimuli can make consumers gradually form emotional feedback, consumers will gradually like the stimulation, and then unconsciously stimulate the formation of preferences (Zajonc, 1980) [17]. Therefore, the mere exposure effect can make the audience have a certain preference for sponsor information (Bennett, 1999) [18], and help them to recall brand information.

- From the low level of cognitive processing. Low levels of cognitive processing of information is through peripheral route for processing information, for example, information in the stadium (sponsor sponsor Logo and other sponsorship information) will affect the consumer's sponsor memory (Cornwell and Relyea, 2000) [19].

- From the point view of stimulus reactivation. Whether the advertisement fragment was noticed by the previous or not, the positive attitude of the brand to the brand will be reactivated again by the advertisement fragment (Pham and Vanhuele, 1997) [20].

- From the perspective of matching. The most important area of previous research is the matching between sponsors and sponsorship activities, and it is easier to remember the information consistent with previous expectations (matching, congruence, fit, relatedness, similarity) (Speed and Thompson, 2000)[21].

- From the perspective of sponsorship relationship. The interpretation of sponsorship relationship has not only significant interaction with the matching, but also a greater impact on the recall of the respondents than the high consistency in the case of low consistency (Cornwell and Humphreys, 2006) [22]. 


\section{Social Environmental Factors}

It is admitted that the social environment has a huge impact on sports sponsorship events. Generally, the social environ-mental factors are mainly reflected in four aspects: legal factor, economic factor, cultural factor, educational factor. Nowadays, current laws and regulations in China have still not clearly defined the nature of sports sponsorship. For example, whether the nature of a signed sponsorship agreement belongs to a donation or a gift. And there is no effective restraint on its delinquent party. In economic factor, sports events and sponsors are not completely independent individual, which means that a great many companies could consider sports sponsorship as a method to obtain economic benefits as well as a way to develop the sports industry. Furthermore, the more developed countries are, the better sports sponsorship is. In cultural factor, the traditional national sport and the popular sports in one country have great influence on what kind of sports event could be sponsored and how much it would be paid. For instance, table tennis has been the national ball game which catches most of the attention of China, attracting multi-kind sponsors, such as dairy companies, automobiles, petrochemical enterprises etc. While millions of Americans have been into basketball and football, thus there is no doubt that hundreds of sports sponsorship agreements are signed in the NBA and in the Superbowl. Finally, the degree of sports sponsorship is decided on the basis of staff's education levels and their good strategic thinking, copywriting ability, workflow control, proposal and strong execution.

TABLE I. THE INFLUENCE FACTORS OF SPORTS SPONSORSHIP EFFECTIVENESS

\begin{tabular}{|l|l|l|}
\hline $\begin{array}{c}\text { Consumer } \\
\text { characteristic factors }\end{array}$ & \multicolumn{1}{|c|}{$\begin{array}{c}\text { Cognitive } \\
\text { processing factors }\end{array}$} & $\begin{array}{c}\text { Social environmental } \\
\text { factors }\end{array}$ \\
\hline Individual & Mere exposure & Legal factor \\
involvement & Low-level & Economic factor \\
Attitude towards & cognitive & Cultural factor \\
sponsorship & processing & Educational factor \\
Perceived & Stimulus & \\
authenticity of & reactivation & \\
the sponsors & Matching & \\
Familiarity with & Sponsorship & \\
the sponsorship & rrelationship & \\
of the brand & rarticulation & \\
Perceived fit & & \\
Demographic & & \\
characteristics & & \\
\hline
\end{tabular}

\section{EVALUATION OF SPORTS SPONSORSHIP EFFECTIVENESS}

Compared to the prosperous development of sports sponsorship, its evaluation methods are still in budding stage. Admittedly, current widely used evaluation methods include exposure-based method, experimental method, tracking technology, and enterprises self-assessment method. Exposure-based method is probably the method that sponsors calculate the number of tv/radio seconds or centimeters/column and the estimation of the direct and indirect audiences of the sponsored event through sponsorship. Then, experimental method focuses on the audience response to sponsor's image or awareness, consumers' attitudes toward sponsors and sponsorship, etc. thus measures sponsorship effectiveness. Another approach is tracking technology which measures the changes of consumers' brand awareness, familiarity, preference through sports sponsorship. Finally, sponsors can evaluate the effectiveness of sports sponsorship by checking whether they achieve their image objectives.

This paper establishes the sports sponsorship effectiveness evaluation mode from three perspectives, that is, from customers' perspective, from cooperative perspective, from social benefits perspective.

\section{A. From Customers' Perspective}

There are probably various sports sponsorship objectives (e.g. increasing media exposure, increasing brand awareness, improving enterprise image, promoting competitive ability, boosting sales revenue, etc.). Based on literature review and expert review, this paper argues that the profitability, brand equity and relationship object are the three important elements of the sponsorship success. Thus, sponsors could evaluate the effectiveness of sponsorship and adjust their sponsorship accordingly by comparing the changes on profitability, brand equity and relationship objects before and after the sponsorship. The sports sponsorship, which is different from the traditional one-way communication tools, is the combination of the sponsors, the recipients, the media, the public and others who are involved in this sponsorship communication process. Obviously, sports sponsorship is the promotion agent for establishing an effective and efficient trading network between sponsor enterprises and customers.

\section{B. From Corporative Perspective}

There are probably various sports sponsorship objectives (e.g. increasing media exposure, increasing brand awareness, improving enterprise image, promoting competitive ability, boosting sales revenue, etc.). Based on literature review and expert review, this paper argues that the profitability, brand equity and relationship objects are the three important elements of the sponsorship success. Thus, sponsors could evaluate the effectiveness of sponsorship and adjust their sponsorship accordingly by comparing the changes on profitability, brand equity and relationship objects before and after the sponsorship. The sports sponsorship, which is different from the traditional one-way communication tools, is the combination of the sponsors, the recipients, the media, the public and others who are involved in this sponsorship communication process. Obviously, sports sponsorship is the promotion agent for establishing an effective and efficient trading network between sponsor enterprises and customers.

\section{From Social Benefits Perspective}

There is no doubt that sports sponsorship could promote related sport industry rapidly and healthily meanwhile booming public health growth. Sports sponsorship can relieve the tension of sports funds so that it is beneficial for improving the material basis in competitive sports as well as public health facilities. In the first place, sports sponsorship has been compensated for the lack of the funds for sports departments and become an important source of sports 
funding, alleviating the contradiction of financial difficulties. In addition, it is quite effective to boost the varying income of athletes, particularly the football and basketball players, which not only make the stable and creative athletes team, but also inspire and cultivate the potential reserve sports talents. Furthermore, sports sponsorship greatly enriches the leisure life for the public and meets the needs of sports fans through activating more various forms of sports events in "Fig. 2".

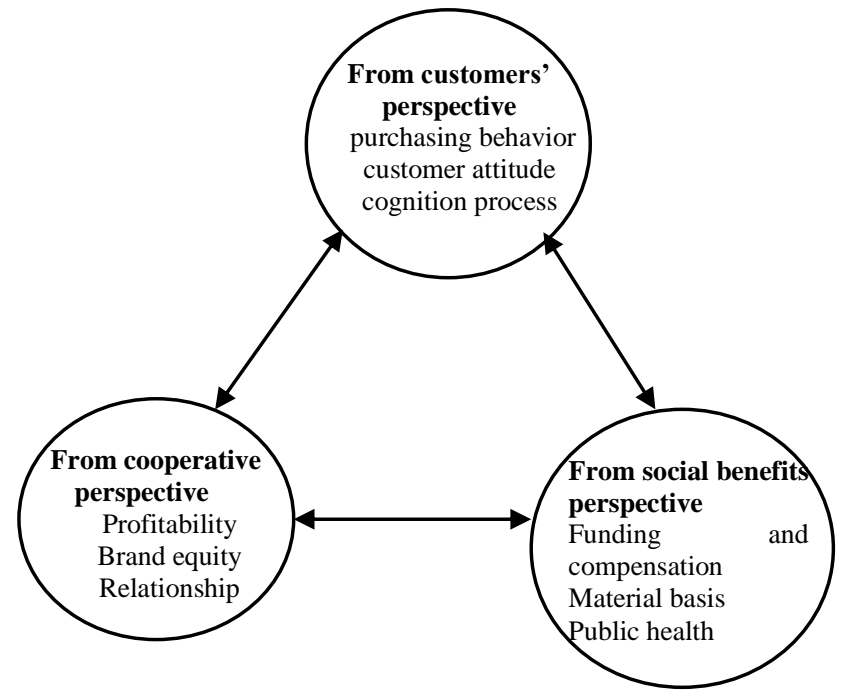

Fig. 2. Sports sponsorship effectivenenss evaluation mode.

\section{CONCLUSION}

With the wide and profound influence of sports events on the social life, sports sponsorship has been a marketing tool of enterprises propaganda image, information and increase consumer awareness and enhance the brand effective. This paper draws the following conclusions:

The sports sponsorship effectiveness mainly displays in the following five aspects: custromer-based brand equity, brand integration, brand loyalty, sponsor image, stakeholders.

The effect factors of sports sponsorship effectiveness includes: consumer characteristics factors, cognitive processing factors, and environmental factors.

This paper establishes the sports sponsorship effectiveness evaluation mode from three perspectives, that is, from customers' perspective, from cooperative perspective, from social benefits perspective. A number of research results show that it is reasonable, feasible and effective to apply this sports sponsorship effectiveness mode with three perspectives comprehensively.

\section{REFERENCES}

[1] S. Sleight, Sponsorship: What it is and how to use it. Maidenhead Berkshire, McGraw-Hill,1989.

[2] C. Brooks, "Sponsorship: strictly business." Athletic Business,vol. 10, pp. 59-62, 1990.
[3] R. E. McCarville and R. P. Copeland, "Understanding sport sponsorship through exchange theory." Journal of Sport Management,vol. 8, pp. 102-114, 1994.

[4] Bao Minxiao. Sports industry: new economic growth point. Beijing, People's Sports Publishing House of China, 2000

[5] Huang Ke. On sports sponsorship. Journal of Chengdu Sport University ,vol. 1, pp. 32-35, 2001

[6] Yu Chengshi. Sports sponsorship strategy. Shijiazhuang, Hebei Science \&Technology Publishing House, 2007

[7] Huang Shuru, Research on the management of professional sport sponsorship in Taiwan area, Institute of Business Management, National Chiao Tung University, 1999.

[8] S. K. Balasubramanian and J. A. Karrh, et al., "Audience response to product placements: An integrative framework and future research agenda." Journal of Advertising, vol. 3, pp. 115-141, 2006.

[9] T. B. Cornwell, "Sponsorship-linked marketing development." Sport Marketing Quarterly, vol. 4, pp. 13-24, 1995.

[10] Reinhard Grohs and Heribert Reisinger, Sponsorship effects on brand image: The role of exposure and activity involvement, Journal of Business Research, vol. 5, pp. 1018, 2014

[11] R. Madrigal, "The influence of social alliances with sports teams on intentions to purchase corporate sponsors' products." Journal of Advertising, vol. 4, pp. 13-24, 2000.

[12] E. L. Olson, "Does sponsorship work in the same way in different sponsorship contexts?" European Journal of Marketing,vol.1, pp.180199, 2010.

[13] M. Walraven and R. H. Koning, et al. , "The effects of sports sponsorship: A review and research agenda." Marketing Review,vol. 1, pp. 17-38, 2012.

[14] C. Pestana Barros and A. L. Silvestre, "An evaluation of the sponsorship of Euro 2004." international journal of sports marketing and sponsorship ,vol. 3, pp. 192-212,2006.

[15] M. T. Pham and G. V. Johar, "Market prominence biases in sponsor identification: Processes and consequentiality." Psychology and Marketing,vol. 2, pp. 123-143, 2001.

[16] L. Kinney and S. R. McDaniel, et al., "Demographic and psychographic variables predicting NASCAR sponsor brand recall." International Journal of Sports Marketing \& Sponsorship, vol. 3, pp. 169-179, 2008

[17] R. B. Zajonc, "Feeling and thinking: Preferences need no inferences." American psychologist, vol. 2, pp. 151,1980.

[18] T. B. Cornwell, and G. E. Relyea, et al. , "Understanding long-term effects of sports sponsorship: role of experience, involvement, enthusiasm and clutter." International Journal of Sports Marketing and Sponsorship, vol. 2, pp. 127-144, 2000.

[19] R. Bennett, "Sports sponsorship, spectator recall and false consensus." European Journal of Marketing, vol. 3, pp. 291-313,1999.

[20] M. T. Pham and M. Vanhuele, "Analyzing the memory impact of advertising fragments." Marketing letters, vol. 4, pp. 407-417, 1997.

[21] R. Speed and P. Thompson, "Determinants of sports sponsorship response." Journal of the Academy of Marketing Science ,vol. 2, pp. 226, 2000.

[22] T. B. Cornwell and M. S. Humphreys, et al., "Sponsorship-linked marketing: The role of articulation in memory." Journal of consumer research,vol.3,pp. 312-321, 2006. 